\title{
Voltammetry of Immobilized Cytochrome c on a Novel Binary Self-Assembled Monolayers of Thioctic Acid and Thioctic
}

\author{
Amide Modified Gold Electrodes
}

\author{
Xueping Ji ${ }^{\mathrm{a}}$, Baokang Jin ${ }^{\mathrm{a}, \mathrm{b}}$, Jiye Jin ${ }^{\mathrm{a}}$, and Toshio Nakamura ${ }^{\mathrm{a}, *}$ \\ a Department of Chemistry, Faculty of Science, Shinshu University, Matsumoto 390-8621, Japan

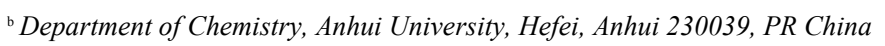

Published in: Journal of Electroanalytical Chemistry. 590(2): 173-180 (2006) 


\section{Abstract}

Horse heart cytochrome c (cyt c) was adsorbed on the binary self-assembled monolayers (SAMs) composed of thioctic acid (T-COOH) and thioctic amide $\left(\mathrm{T}-\mathrm{NH}_{2}\right)$ at gold electrodes via electrostatic interaction. The cyt $\mathrm{c}$ adsorbed on the modified gold electrode exhibited well-defined reversible electrochemical behavior in $10 \mathrm{mM}$ phosphate buffer solution (PBS, pH 7.0). The surface concentration $(\Gamma)$ of electroactive species, cyt $\mathrm{c}$, on the binary SAMs was higher than that in single-component SAMs of T-COOH, and reached a maximum value of $9.2 \times 10^{-12} \mathrm{~mol} \mathrm{~cm}^{-2}$ when the ratio of $\mathrm{T}-\mathrm{COOH}$ to $\mathrm{T}-\mathrm{NH}_{2}$ in adsorption solution was of $3: 2$, and the formal potential $\left(E^{\circ^{\prime}}=\left(E_{\mathrm{pa}}+E_{\mathrm{pc}}\right) / 2\right)$ of cyt $\mathrm{c}$ was $-0.032 \mathrm{~V}(v s . \mathrm{Ag} \mid \mathrm{AgCl}(3 \mathrm{M} \mathrm{NaCl}))$ in a $10 \mathrm{mM}$ PBS. The interaction between cyt $\mathrm{c}$ and the binary SAMs made the $E^{\circ}$ shift negatively when compared with that of cyt $\mathrm{c}$ in solution $(+0.258 \mathrm{~V} v s$. NHE, i.e. $+0.058 \mathrm{~V} v s . \mathrm{Ag} \mid \mathrm{AgCl}(3 \mathrm{M} \mathrm{NaCl}))$. The fractional coverage of bound cyt $\mathrm{c}$ was a 0.64 theoretical monolayer. The standard electron transfer rate constant of cyt $\mathrm{c}$ immobilized on the binary SAMs was also higher than that on single-component SAMs of T-COOH, and the maximum value of $15.8 \pm 0.6 \mathrm{~s}^{-1}$ was obtained when the ratio of T-COOH to $\mathrm{T}-\mathrm{NH}_{2}$ in adsorption solution was at 3:2. The results suggest that the electrode modified with the binary SAMs functions better than the electrode modified with single-component SAMs of T-COOH.

Keywords: Self-assembled monolayer; Cyclic voltammetry; Cytochrome c; Gold electrode

\section{Introduction}

Since the publication of studies on direct electron transfer between cytochrome c (cyt c) and electrode [1,2], there have been rapid developments in the use of new electrochemical devices to study the redox process of protein [3-5].

The electrochemistry of cyt $\mathrm{c}$ at gold electrodes modified with single component self-assembled monolayers (SAMs) of carboxylic acid terminated $(\mathrm{COOH})$ alkanethiols has been studied most commonly [6-14]. The COOH SAMs have proven to be an excellent interface for the immobilization and electrochemical characterization of cyt $\mathrm{c}$. The voltammetric response of cyt $\mathrm{c}$ immobilized on $\mathrm{COOH}$ SAMs at gold electrode can be very stable and reproducible, but deviations from the expected response for an ideal adsorbed redox system have been observed [13]. Especially, the voltammograms often display anomalous broadening.

Recent studies have shown that certain types of binary SAMs are known to exhibit randomly phase separation, making it highly conducive to cyt $\mathrm{c}$ adsorption and electron transfer [15]. The electrochemical response of cyt c immobilized on binary SAMs composed of $\mathrm{COOH} / \mathrm{OH}[15,16]$ and $\mathrm{COOH} / \mathrm{CH}_{3}[17,18]$ terminated alkanethiols were improved obviously, compared to that 
observed for cyt c immobilized on the single-component COOH SAMs.

Based on previous studies [13-18], we found that different types of monolayer surface could exert effects on the extent of adsorption and electrochemical behavior of cyt c. Although alkanethiols with different chain lengths were used for $\mathrm{COOH} / \mathrm{OH}$ and $\mathrm{COOH} / \mathrm{CH}_{3}$ terminated SAMs, the stability of the SAMs and effective electron transfer couldn't be improved at the same time. Longer-chain alkanethiols SAMs were more stable due to stronger Van der Waals forces among longer-chain alkanethiols, whereas much slower electron transfer rate was obtained due to an increase in electron transfer distance [19, 20]. For example, an electron transfer rate constant of $0.1 \mathrm{~s}^{-1}$ was obtained with SAMs composed of longer-chain 16-mercaptohexadecanoic acid [20]. For shorter-chain alkanethiol SAMs, the electron transfer rate constant could be increased, however, the stability of SAMs was not higher than that of longer-chain. Thioctic acid (T-COOH), with disulfide-containing bases, short alkyl chain with four $\mathrm{CH}_{2}$ units, has distinct advantages for gold electrode modification [21]. The disulfide-containing bases yields two gold-sulfur bonds with the surface of gold electrode, which gives an additional stability, compared with the single gold-sulfur bond. Formation and characterization of single-component SAMs of T-COOH on gold electrodes have been monitored by different methods [21-23]. This single-component SAMs is stable in PBS and in buffered hexacyanoferrate $(2+/ 3+)$ solution [22]. The combination of thioctic acid (T-COOH) and thioctic amide $\left(\mathrm{T}-\mathrm{NH}_{2}\right)$ is expected to have distinct advantages for gold electrode modification and immobilization of protein. The components of the terminal groups of the SAMs composed of $\mathrm{T}-\mathrm{COOH}$ and $\mathrm{T}-\mathrm{NH}_{2}$, amino and carboxyl, can match the residual groups $\left(-\mathrm{NH}_{2}\right.$ and $\left.-\mathrm{COOH}\right)$ of protein, making the interaction between SAMs and protein strong and the amount of adsorbed protein increase, because the interaction between SAMs and protein is promoted not only by electrostatic interaction but also by steric effect and hydrogen-bond formation. Therefore, in order to enhance the stability of SAMs and to improve electron transfer rate, we select T-COOH and T-NH to fabricate binary SAMs in this paper. It may provide superior gold surface attachment of cyt $\mathrm{c}$ for the electrochemical investigation.

The effect of the ratios of $\mathrm{T}-\mathrm{COOH}$ to $\mathrm{T}-\mathrm{NH}_{2}$ in solution on the absorption and the electrochemistry of cyt $\mathrm{c}$ is studied in this paper. Additionally, the effect of ionic strength and $\mathrm{pH}$ value on cyclic voltammetric behavior of the electrodes is also investigated.

Many different methods are used for the characterization of the SAMs [22, 24-28]. Electrochemical methods used in the SAMs characterization are mainly cyclic voltammetry [28] and electrochemical impedance spectroscopy [22]. Cyclic voltammetry is used to determine the capacitance of the electrode, and to investigate the kinetics of redox couple, hexacyanoferrate in this paper. 


\section{Experimental}

\subsection{Materials}

Horse heart cyt c, obtained from Sigma, was used without further purification. Thioctic acid (T-COOH) and thioctic amide (T- $\left.\mathrm{NH}_{2}\right)$, obtained from Aldrich Chemical Co. Inc., dissolved in anhydrous ethanol. Potassium ferricyanide, sulfuric acid, and hydrogen peroxide (30\%, w/v solution) were purchased from Wako Pure Chemical, Co. Ltd., and used as received.

Phosphate buffer solutions (PBS) were prepared from disodium hydrogen phosphate and potassium dihydrogen phosphate (Wako), with the $\mathrm{pH}$ adjusted with potassium hydroxide or phosphoric acid. Four mM PBS, pH 7.0, was used for the preparation of cyt c electrode, and $10 \mathrm{mM}$ PBS, pH 7.0, served for recording of cyclic voltammograms and for further experiments.

\subsection{Electrochemical Measurement}

Cyclic voltammetry was carried out using a computer controlled electrochemistry workstation at ambient temperature $\left(23 \pm 2^{\circ} \mathrm{C}\right)$. A conventional three-electrode system was used. The working electrode was a modified gold electrode with binary SAMs of T-COOH and $\mathrm{T}-\mathrm{NH}_{2}$, and the reference electrode was an $\mathrm{Ag} \mid \mathrm{AgCl}(3 \mathrm{M} \mathrm{NaCl}$, from Bioanalytical System Inc.). The counter electrode was a platinum wire.

\subsection{Preparation of modified electrode}

The gold electrode was prepared with polycrystalline gold $\operatorname{rod}(2 \mathrm{~mm} \Phi)$ housed in a Teflon tube. The electrodes were carefully polished first with emery paper (No.2500), and then with $0.05 \mu \mathrm{m}$ alumina slurry on microcloth pads. After removal of the trace alumina from the surface by rinsing with water, the electrodes were ultrasonicated for $10 \mathrm{~min}$ in fresh Piranha solution $\left(\mathrm{H}_{2} \mathrm{SO}_{4}: \mathrm{H}_{2} \mathrm{O}_{2}\right.$ $=3: 1(\mathrm{v} / \mathrm{v}))$. Warning: Piranha solution reacts violently with organic solvents. The electrodes were then ultrasonicated in water, acetone, and water again for $5 \mathrm{~min}$, respectively. After being rinsed with water and dried in nitrogen gas flow, the electrodes were incubated in a $10 \mathrm{mM}$ anhydrous ethanol solution of T-COOH and $\mathrm{T}-\mathrm{NH}_{2}$ at $4{ }^{\circ} \mathrm{C}$ for ca. $48 \mathrm{hrs}$. The modified electrodes were rinsed in turn with ethanol and $4 \mathrm{mM}$ PBS (pH 7.0), to remove physically adsorbed T-COOH and T- $\mathrm{NH}_{2}$. The electrodes modified with binary SAMs of $\mathrm{T}-\mathrm{COOH}$ and $\mathrm{T}-\mathrm{NH}_{2}$ are denoted as $\mathrm{T}-\mathrm{COOH}+\mathrm{T}-\mathrm{NH}_{2} \mid \mathrm{Au}$ in the text. Then the modified gold electrodes were incubated in $0.5 \mathrm{mg} \mathrm{mL}^{-1}$ cyt $\mathrm{c}$ in $4 \mathrm{mM}$ PBS, $\mathrm{pH}=7.0$. During cyt $\mathrm{c}$ adsorption, the electrodes were cycled ranging from -0.25 to $+0.25 \mathrm{~V}$ with a scan rate of $20 \mathrm{mV} \mathrm{s}^{-1}$ for 20 cycles. After rinsing with $10 \mathrm{mM}$ PBS (pH 7.0), the 
electrochemical behavior of the immobilized cyt $\mathrm{c}$ was characterized by cyclic voltammetry in 10 $\mathrm{mM}$ PBS (pH 7.0). The cyt c immobilized electrodes, as shown in scheme 1, are denoted as cyt $\mathrm{c} / \mathrm{T}-\mathrm{COOH}+\mathrm{T}-\mathrm{NH}_{2} \mid \mathrm{Au}$ electrode in the text.

Scheme 1.

\section{Results and discussion}

\subsection{Characterization of modified electrode surface}

In order to compare the blocking characteristics of SAMs prepared from different ratios of $\mathrm{T}-\mathrm{COOH}$ to $\mathrm{T}-\mathrm{NH}_{2}$ solution, cyclic voltammetry was performed with hexacyanoferrate $(2+/ 3+)$ solution. Fig. 1 illustrates the voltammetric behavior of the bare and the modified electrodes. The bare $\mathrm{Au}$ electrode in hexacyanoferrate solution $\left(1 \mathrm{mM}\left[\mathrm{Fe}(\mathrm{CN})_{6}\right]^{3-} /\left[\mathrm{Fe}(\mathrm{CN})_{6}\right]^{4-}\right.$ in $\left.0.1 \mathrm{M} \mathrm{NaCl}\right)$ showed a well-defined faradaic response. In contrast, the cyclic voltammograms for electrodes prepared with T-COOH and $\mathrm{T}-\mathrm{NH}_{2}$ at the ratios of 5:0, 4:1, and 3:2 showed effective blocking for this redox couple, respectively. It is attributed to repulsing interaction of the negative charge of SAMs to negatively charged redox couple $\left(\left[\mathrm{Fe}(\mathrm{CN})_{6}\right]^{3-} /\left[\mathrm{Fe}(\mathrm{CN})_{6}\right]^{4-}\right)$. However, a small response of the redox couple was observed when the ratio of two thiols was 1:1, and it increased with the increasing of the proportion of T-NH $\mathrm{N}_{2}$. It may arise from the decreasing repulsion between the redox couple and SAMs with increasing of $\mathrm{T}-\mathrm{NH}_{2}$.

Fig. 1

In addition, the determination of double layer capacitance was carried out for providing a further understanding of characteristics for the modified electrode surface. Since capacitance current is proportional to electrode active area, the capacitance current obtained at SAMs modified electrodes provides a direct measurement of the coverage of electrode surface. The double layer capacitance of the modified electrodes and bare electrode was determined using the following equation [29]:

$$
i_{\mathrm{c}}=v A C_{\mathrm{d}}
$$

where $i_{\mathrm{c}}(\mathrm{A})$ is capacitive current contribution to anodic current, $v\left(\mathrm{~V} \mathrm{~s}^{-1}\right)$ is scan rate, $A\left(\mathrm{~cm}^{-2}\right)$ is electrode area, and $C_{\mathrm{d}}\left(\mathrm{F} \mathrm{cm}^{-2}\right)$ is the double layer capacitance. Cyclic voltammetry was carried out in $0.1 \mathrm{M} \mathrm{KCl}$ solution at the scanning range from -400 to $+400 \mathrm{mV}$. The charging current was measured at $100 \mathrm{mV}$. A plot of relative percentage change in double layer capacitance vs. percentage content of T-COOH in the adsorption solution was obtained, and the results are showed in Fig. 2. 
Fig. 2.

A decrease of ca. $80 \sim 90 \%$ in the double layer capacitance was observed for the SAMs prepared from all ratios of two thiols and the percentage decrease in double layer capacitance was independent on the ratios of two thiols in adsorption solution. This seems to arise from the formation of a more densely packed SAMs at the surface of gold electrode. However, the results also indicated that there was still small portion of gold surface uncovered by SAMs and might be permeable to small ions, e.g., $\mathrm{K}^{+}$and $\mathrm{Cl}^{-}$.

\subsection{Electrochemistry of cyt $\mathrm{c}$ at modified gold electrodes}

\subsubsection{Electrochemical behavior of cyt c at modified gold electrodes}

The modified gold electrode was exposed to a cyt c solution, and cyclic voltammograms were obtained, as shown in Fig. 3. A pair of well-defined redox peaks appeared in 4 mM PBS (pH 7.0) containing low concentration cyt $\mathrm{c}$ and gradually increased in peak current as the scanning time increased during the first 20 cycles, and then remained unchanged.

Fig. 3.

In order to understand the concentration effect of cyt $\mathrm{c}$ on voltammetric behavior, the measurements were conducted in various concentrations of cyt c in $4 \mathrm{mM}$ PBS (pH 7.0) and the results are shown in Fig. 4. As the concentration of cyt $\mathrm{c}$ increased from $0.05 \mathrm{mg} \mathrm{mL}^{-1}$ to $1.0 \mathrm{mg}$ $\mathrm{mL}^{-1}$, the shape of the voltammograms gradually evolved from reversible to quasi-reversible, and finally no obvious oxidation peaks. It is attributed to a self-inhibition effect due to surface blockage.

Fig. 4.

Fig. 5.

The electrodes adsorbed cyt $\mathrm{c}$ were rinsed twice with $10 \mathrm{mM}$ PBS prior to immersion in a blank solution. The cyclic voltammograms obtained in $10 \mathrm{mM}$ PBS (pH 7.0) at a scan rate of $40 \mathrm{mV} \mathrm{s}^{-1}$ were shown in Fig. 5. A pair of well-defined reversible redox peaks occurred after adsorption from $0.05 \mathrm{mg} \mathrm{mL}^{-1}$ cyt c solution (Fig. 5(b)). The formal potential, $E^{\circ}$, taken as the average of $E_{\mathrm{pc}}$ and $E_{\mathrm{pa}}$, was $-0.032 \mathrm{~V}$, with $\Delta E_{\mathrm{p}}$, the peak-to-peak potential separation of anodic and cathodic waves, $0.010 \mathrm{~V}$, at the scan rate of $40 \mathrm{mV} \mathrm{s}^{-1}$. The redox peak currents (the ratio of the anodic and cathodic peak 
currents was close to 1.0) were directly proportional to the potential scan rates at low scan rates, as shown in Fig. 6, which is the characteristic of a typical surface adsorption controlled process. However, the $E^{0^{\prime}}$ values shift positively and $\Delta E_{\mathrm{p}}$ values increase as the cyt c concentration of the adsorption solution increases from 0.10 to $1.00 \mathrm{mg} \mathrm{mL}^{-1}$, resulting in quasi-reversible redox peaks (Fig. 5(c,d,e)). So a cyt c concentration of $0.05 \mathrm{mg} \mathrm{mL}^{-1}$ in the adsorption solution was chosen in all further experiments.

Fig. 6

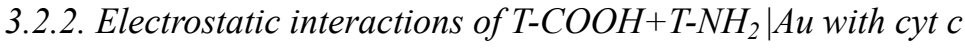

The $E^{\circ}$ of cyt c adsorbed on T-COOH+T- $\mathrm{NH}_{2} \mid \mathrm{Au}$ surface was $-0.032 \mathrm{~V}$ (vs. $\mathrm{Ag} \mid \mathrm{AgCl}(3 \mathrm{M} \mathrm{NaCl})$ ) in $10 \mathrm{mM}$ PBS ( $\mathrm{pH} 7.0$ ), which shifted negatively compared to that of cyt $\mathrm{c}$ in solution (+ $0.258 \mathrm{~V}$ vs. NHE, i.e. $+0.058 \mathrm{~V}$ vs. $\mathrm{Ag} \mid \mathrm{AgCl}(3 \mathrm{M} \mathrm{NaCl}))[30]$. This shift was commonly observed when cyt $\mathrm{c}$ binds to membranes and other surface [19,31-34]. For example, electrostatic adsorption of cyt $\mathrm{c}$ to $\mathrm{HS}\left(\mathrm{CH}_{2}\right)_{15} \mathrm{COOH}$ and $\mathrm{HS}\left(\mathrm{CH}_{2}\right)_{10} \mathrm{COOH}$ monolayer electrodes lead negative shift of formal potential ca. $60 \sim 80 \mathrm{mV}$ compared with the case in the solution. And the redox potential undergoes a further negative shift of ca. $20 \mathrm{mV}$ for covalent immobilization to $\mathrm{HS}\left(\mathrm{CH}_{2}\right)_{15} \mathrm{COOH}[19,20]$. The shift arose from a stronger binding of the oxidized form, which could be understood from the ratio of surface binding constant for the oxidized and reduced forms of redox couple $[35,36]$. The ratio, $K_{\text {Ox }} / K_{\text {Red }}$, can be estimated by the following equation:

$E_{\mathrm{b}} \mathrm{o}^{\prime}-E_{\mathrm{f}}^{\mathrm{o}^{\prime}}=-R T /(n F) \ln \left(K_{\mathrm{OX}} / K_{\text {Red }}\right)$

where $E_{\mathrm{b}}{ }^{\circ}$ and $E_{\mathrm{f}}{ }^{\circ \prime}$ are the formal potentials of the couple in the bound and free forms, respectively. $K_{\mathrm{Ox}}$ and $K_{\mathrm{Red}}$ are the corresponding binding constants for the oxidized and reduced species. Comparing the $E^{\circ^{\prime}}$ values of cyt $\mathrm{c}$ in solution and on T-COOH+T-NH $\mathrm{N}_{2} \mid \mathrm{Au}$ surface, a limiting shift of $-0.090 \mathrm{~V}$ was obtained, which gave a $K_{\mathrm{OX}} / K_{\mathrm{Red}}$ ratio of 34 , indicated that the interaction between the oxidized form of cyt $\mathrm{c}$ with $\mathrm{T}-\mathrm{COOH}+\mathrm{T}-\mathrm{NH}_{2} \mid \mathrm{Au}$ surface is much stronger than that of the reduced form, indicating the reduced form was much more stable for the unfolding of the protein when protein interacted with SAMs. This is attributed to a larger Gibbs energy of folding of the reduced form than that of the oxidized form [37]. On the other hand, the shift might arise from the unfolding of cyt $\mathrm{c}$, especially for oxidized form of cyt $\mathrm{c}$ due to enhanced electronic coupling on the cyt $\mathrm{c} / \mathrm{SAMs}$ interface [38].

\subsubsection{The surface concentration $(\Gamma)$ of cyt $c$ on the modified gold electrode surface and the electron} transfer rate constants

For an ideal Nernstian behavior of surface-confined nonreacting species, the peak current is directly proportional to the surface coverage $(\Gamma)$ and potential scan rate [39]: 
$i_{p}=n^{2} F^{2} \Gamma v A /(4 R T)$

where $n$ is the number of electrons transferred, and the other symbols have their usual meanings. In practice, the ideal behavior is approached at relatively slow scan rate for an adsorbed layer that shows no intermolecular interactions. The surface concentration $(\Gamma)$ of cyt $\mathrm{c}$ on the modified gold electrode surface can be calculated by the slope of the line in Fig. 6, according to the equation (3). The results were listed in Table 1 . The deviation from linearity and the increase in $\Delta E_{\mathrm{p}}$ with increasing scan rate were observed at high scan rate, indicating that the electron transfer kinetics was quasi-reversible.

The electron transfer rate constants were obtained from Laviron theory [40]. Approximate values of $\alpha$ can be deduced to be close to 0.5 for a quasi-reversible redox system, $\mathrm{n} \Delta E_{\mathrm{p}}<200 \mathrm{mV}$, according to the literature [40]. The difference of $\Delta E_{\mathrm{p}}$ does not depend very much on $\alpha$ when it is between 0.3 and 0.7 . The present system was quasi-reversible, $\mathrm{n} \Delta E_{\mathrm{p}}<200 \mathrm{mV}$, according to the relationship between $\mathrm{n} \Delta E_{\mathrm{p}}$ and $m^{-1}$ for $\alpha=0.5$, where $m=T R k /(n F v)$ [40], the standard electron transfer rate constant of the immobilized cyt c could be calculated. A value of $15.8 \pm 0.6 \mathrm{~s}^{-1}$ was obtained at the electrode modified with the ratio of $\mathrm{T}-\mathrm{COOH}$ to $\mathrm{T}-\mathrm{NH}_{2}$ at 3:2 from three different scan rates. The results for the other electrodes are listed in Table 1.

\subsubsection{Effect of the ratios of $\mathrm{T}-\mathrm{COOH}$ to $\mathrm{T}-\mathrm{NH}_{2}$ on voltammetric behavior}

In order to investigate the effect of the ratios of $\mathrm{T}-\mathrm{COOH}$ to $\mathrm{T}-\mathrm{NH}_{2}$ in solution on voltammetric behavior, the solutions of various ratios of $\mathrm{T}-\mathrm{COOH}$ to $\mathrm{T}-\mathrm{NH}_{2}, 5: 0,4: 1,3: 2,1: 1,2: 3,1: 4$, and 0:5, were used to fabricate modified electrode. Table 1 summarizes electrochemical parameters of modified gold electrodes incubated in various ratios of T-COOH to $\mathrm{T}-\mathrm{NH}_{2}$ solution.

Table 1

Electrochemical parameters for the modified gold electrode prepared with various ratios of T-COOH to $\mathrm{T}-\mathrm{NH}_{2}$

\begin{tabular}{cccccccc}
\hline T-COOH:T-NH 2 & $\Gamma \times 10^{12} / \mathrm{mol} \mathrm{cm}^{-2}$ & $\theta^{a}$ & $k^{b} / \mathrm{s}^{-1}$ & $E^{\mathrm{o}^{\prime}} / \mathrm{mV}$ & $\Delta E_{\mathrm{p}}{ }^{c} / \mathrm{mV}$ & $\Delta E_{1 / 2}{ }^{d} / \mathrm{mV}$ & $i_{\mathrm{p}}{ }^{e} / \mathrm{nA}$ \\
\hline $5: 0$ & 5.0 & 0.35 & $9.5 \pm 0.7$ & -32 & 36 & 107 & 12 \\
$4: 1$ & 7.8 & 0.55 & $9.2 \pm 0.6$ & -23 & 28 & 105 & 24 \\
$3: 2$ & 9.2 & 0.64 & $15.8 \pm 0.6$ & -32 & 10 & 91 & 26 \\
$1: 1$ & 7.4 & 0.52 & $15.2 \pm 0.6$ & -33 & 20 & 98 & 19 \\
$2: 3$ & 6.1 & 0.43 & $14.5 \pm 0.4$ & -23 & 19 & 103 & 18 \\
$1: 4$ & 3.1 & 0.22 & $13.7 \pm 0.6$ & -29 & 24 & 105 & 9 \\
$0: 5$ & 2.6 & 0.18 & $14.0 \pm 0.8$ & -23 & 22 & 105 & 8 \\
\hline
\end{tabular}

${ }^{a} \theta$ is the fraction of monolayer coverage by cyt $\mathrm{c}$ based on an electrode geometric area of $0.314 \mathrm{~cm}^{2}$ and the theoretical monolayer concentration of $14.3 \times 10^{-12} \mathrm{~mol} \mathrm{~cm}^{-2}$. 
${ }^{b}$ Aveage of measurements with different scan rate $\pm s$.

${ }^{c}$ Scan rate: $40 \mathrm{mV} \mathrm{s}^{-1}$.

${ }^{d}$ Scan rate: $100 \mathrm{mV} \mathrm{s}^{-1} ; \Delta E_{1 / 2}$ is the total width at half-height of the wave.

${ }^{e}$ Scan rate: $100 \mathrm{mV} \mathrm{s}^{-1}$.

The value of $\Gamma$ was not very high at single-component, T-COOH, modified electrode, but it increased with the increase of the proportion of $\mathrm{T}-\mathrm{NH}_{2}$ in adsorption solution and reached a high level at the ratios of $\mathrm{T}-\mathrm{COOH}$ to $\mathrm{T}-\mathrm{NH}_{2}$ ranging from 4:1 to 2:3. After that, it decreased again.

The values of $k$ were higher at ratios of T-COOH to $\mathrm{T}-\mathrm{NH}_{2}$ in solution ranging from 3:2 to $0: 5$, and $i_{\mathrm{p}}$ were higher at ratios of T-COOH to T- $\mathrm{NH}_{2}$ ranging from 4:1 to $2: 3$ in solutions. All further experiments utilized the solution of the ratio of $3: 2$ to fabricate modified electrode, according to these results.

The standard electron transfer rate constant for SAMs with alkanethiol depended on the length of the alkyl chain exponentially [15]. The standard electron transfer rate constants obtained in the present experiment were $\sim 100$-fold and 30-fold smaller than that obtained for shorter-chain $\mathrm{C}_{7} \mathrm{COOH}$ SAMs $\left(1000 \mathrm{~s}^{-1}\right)$ and $\mathrm{C}_{10} \mathrm{COOH} / \mathrm{C}_{7} \mathrm{OH}$ mixed SAMs $\left(300 \mathrm{~s}^{-1}\right)$, respectively [15]. However, it was $\sim 150$ times faster than that obtained for longer-chain $\mathrm{C}_{15} \mathrm{COOH}$ SAMs $\left(0.1 \mathrm{~s}^{-1}\right)$ [20], and close to the value of $13.0 \mathrm{~s}^{-1}$ obtained for $\mathrm{C}_{13} \mathrm{COOH} / \mathrm{C}_{10} \mathrm{OH}$ SAMs [14]. The lower electron transfer rate constants obtained in this work might arise from the stronger combination between cyt $\mathrm{c}$ and the binary SAMs, leading to the unfolding of protein.

It is considered that the surface composition of SAMs is usually controlled by the ratio of two thiols in an adsorption solution [41-46]. The effect of the mixing ratio in the absorption solution on the amount and electron transfer rate constant of adsorbed cyt $\mathrm{c}$ attributed to the change of the surface structure of SAMs.

The interaction between cyt $\mathrm{c}$ and SAMs is affected by two main factors. One is electrostatic interaction and the other is steric effect. For pure T-COOH SAMs, although there are more negative charges, the surface microenvironment of T-COOH SAMs may less match the surface groups of cyt c molecules, resulting in a lower amount and electron transfer rate constant of adsorbed cyt $\mathrm{c}$. The $\mathrm{T}-\mathrm{NH}_{2}$ at $\mathrm{SAMs}$ can attract cyt $\mathrm{c}$ molecules under the condition of appropriate space, leading to the increasing of the amount and electron transfer rate constant of adsorbed cyt $\mathrm{c}$.

A very recent paper [47] reveals that the surface mixing ratio was constant without depending on the mixing ratio of thiols in the adsorption solution for the binary SAMs of 2-aminoethanethiol (AET) and 2-mercaptoethane sulfonic acid (MES). In fact, binary SAMs exhibit either homogeneous mixing or phase separation depending on the relative interactions between adsorbed molecules, which can be classified to three cases. Firstly, when the interaction between A-A or B-B is stronger than that of A-B, a monolayer is separated into two types of domains, as mentioned above [41-46]. 
Secondly, the homogeneous mixing takes place when there is no significant difference of the interaction energies between A-A and B-B pairs and the A-B pair [48]. Finally, when the interaction between $\mathrm{A}$ and $\mathrm{B}$ is much stronger than those of the similar molecules, a homogeneously mixed SAMs, whose surface mixing ratio is constant without depending on the mixing ratio of thiols in the adsorption solution were obtained, as has been found in the binary SAMs of AET and MES [47].

In the present study, it might be reasonable to consider that the mixing ratio of SAMs prepared from $\mathrm{T}-\mathrm{COOH}$ and $\mathrm{T}-\mathrm{NH}_{2}$ depends on the ratio of these two thiols in adsorption solution, and it does not belong to the last case.

\subsubsection{Effect of ionic strength and $\mathrm{pH}$ on the electrochemical behavior of cyt $\mathrm{c}$}

The effect of ionic strength on voltammetric behavior was also investigated at the cyt c/T-COOH+T-NH 2 Au electrode in 10 mM PBS (pH 7.0) by adding different concentration of $\mathrm{NaCl}$.

The peak currents decreased with the increase of the concentration of $\mathrm{NaCl}$, i.e., the ionic strength of the solution. This was attributed to the electrostatic interaction between cyt $\mathrm{c}$ and binary SAMs, because it was an important factor governed the incorporation process of cyt $\mathrm{c}$. It was competitive adsorption of cationic ions on the negative sites of the T-COOH and $\mathrm{T}-\mathrm{NH}_{2}$ which resulted in cyt $\mathrm{c}$ desorption from the surface of cyt c/T-COOH+T-NH$H_{2} \mid \mathrm{Au}$ electrode. Although the $E^{0^{\prime}}$ shifted positively as the concentration of $\mathrm{NaCl}$ increased, $\Delta E_{\mathrm{p}}$ was not obviously changed. Moreover, the redox peaks disappeared when the concentration of $\mathrm{NaCl}$ was more than $50 \mathrm{mM}$.

Both the potential and current of cyclic voltammetric peaks were dependent on the $\mathrm{pH}$ of solution. The $E^{0^{\prime}}$ was shifted negatively over the $\mathrm{pH}$ range of 5.0 to 10.0, as shown in Fig. 7, and there was no noticeable change in $\Delta E_{\mathrm{p}}$. The peak currents were higher over the $\mathrm{pH}$ range from 7.0 to 8.0, and decreased gradually from $24 \mathrm{nA}(\mathrm{pH}$ 7.0) to $3 \mathrm{nA}(\mathrm{pH}$ 5.0) with decreasing $\mathrm{pH}$, which can be explained in terms of the competitive interaction of protons with negative sites on the SAMs of T-COOH and T- $-\mathrm{NH}_{2}$. The peak currents decreased from $22 \mathrm{nA}(\mathrm{pH}$ 8.0) to $4 \mathrm{nA}(\mathrm{pH} 10.0)$ as $\mathrm{pH}$ changed from 8.0 to 10.0 . This was due to the change in the cyt $\mathrm{c}$ charged state at different $\mathrm{pH}$. Cyt $\mathrm{c}$ is positively charged at $\mathrm{pH} 7.0$, and the number of positive charges decreased as $\mathrm{pH}$ increased. When $\mathrm{pH}$ is increased to 10.0, cyt $\mathrm{c}$ almost approaches neutral because the isoelectric point ( $\mathrm{pI}$ ) of cyt $\mathrm{c}$ is 10.4 [49], making cyt $\mathrm{c}$ easy to desorb from the surface of the T-COOH+T-NH $\mathrm{H}_{2} \mid \mathrm{Au}$ electrode. In addition, as $\mathrm{pH}$ increases, ferricyt $\mathrm{c}$ is converted into another conformational form called alkaline cyt $\mathrm{c}$, which results in the disruption of the Met 80-Fe bond [50]. Alkaline cyt $\mathrm{c}$ is far more difficult to reduce than native ferricyt $\mathrm{c}[51]$.

Fig. 7.

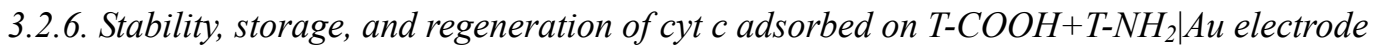


The cyt $\mathrm{c} / \mathrm{T}-\mathrm{COOH}+\mathrm{T}-\mathrm{NH}_{2} \mid \mathrm{Au}$ electrode was quite stable. The cyclic voltammmetry was carried out at one-day intervals over one week, with no significant decrease in peak currents. So the electrode stored in $10 \mathrm{mM}$ PBS (pH 7.0) at $4{ }^{\circ} \mathrm{C}$ for one week could be reused.

On the other hand, if the electrode was incubated in $100 \mathrm{mM} \mathrm{NaCl}$ solution for $5 \mathrm{~min}$, the cyt $\mathrm{c}$ adsorbed on the surface of electrodes was totally desorbed, and exhibited no redox peaks. The electrode was then transferred into water, where it was kept for $10 \mathrm{~min}$ to remove $\mathrm{NaCl}$ adsorbed on the electrode surface. The electrode was then placed in $10 \mathrm{mM}$ PBS (pH 7.0) and stored at $4{ }^{\circ} \mathrm{C}$. Before being used next time, the electrode was exposed to a cyt c solution of $0.05 \mathrm{mg} \mathrm{mL}^{-1}$, then a pair of well-defined redox peaks appeared again.

\section{Conclusion}

In this study, $\mathrm{T}-\mathrm{COOH}$ and $\mathrm{T}-\mathrm{NH}_{2}$ were selected to fabricate SAMs modified gold electrode. The binary SAMs composed of T-COOH and $\mathrm{T}-\mathrm{NH}_{2}$ at the ratios ranging from 5:0 to 3:2 showed an effective electrochemical blocking for ferricyanide and ferrocyanide redox species in $0.1 \mathrm{M} \mathrm{KCl}$. The SAMs prepared from different ratios of two thiols exhibit similar characteristics by the relative percentage decrease in double layer capacitance. The binary SAMs formed in the adsorption solution at the ratio of 3:2 were the most conducive to cyt $\mathrm{c}$ adsorption and electron transfer. The $\mathrm{COOH}$-terminated and $\mathrm{NH}_{2}$-terminated $\mathrm{SAMs}$ produced improvement on the adsorption and electrochemical response of cyt $\mathrm{c}$, compared with single component T-COOH SAMs. The ratios of $\mathrm{T}-\mathrm{COOH}$ to $\mathrm{T}-\mathrm{NH}_{2}$ in adsorption solution exerted effect on the extent of absorption and the electrochemistry of cyt $\mathrm{c}$, which signified that the surface composition of the binary SAMs depended on the ratios of these two thiols in adsorption solution. The incorporated cyt $\mathrm{c}$ was affected by the ionic strength and $\mathrm{pH}$ of solution, indicating the presence of electrostatic interaction between SAMs and cyt $\mathrm{c}$.

\section{References}

[1] P. Yeh, T. Kuwana, Chem. Lett. (1977) 1145.

[2] M.J. Eddowes, H.A.O. Hill, J. Chem. Soc. Chem. Commun. (1977) 771.

[3] M. Fedurco, Coordination Chem. Rev. 209 (2000) 263.

[4] F.A. Armstrong, G.S. Wilson, Electrochim. Acta 45 (2000) 2623.

[5] L. Gorton, A. Lindgren, T. Larsson, F.D. Munteanu, T. Ruzgas, I. Gazargan, Anal. Chim. Acta 400 (1999) 91.

[6] S. Song, R.A. Clark, E.F. Bowden, M.J. Tarlov, J. Phys. Chem. 97 (1993) 6564.

[7] M. Collinson, E.F. Bowden, M.J. Tarlov, Langmuir, 8 (1992) 1247.

[8] M.J. Tarlov, E.F. Bowden, J. Am. Chem. Soc. 113 (1991) 1847. 
[9] T.M. Nahir, E.F. Bowden, J. Electroanal. Chem. 410 (1996) 9.

[10] D. Zhang, G.S. Wilson, K. Niki, Anal. Chem. 66 (1994) 3873.

[11] A. Avila, B.W. Gregory, K. Niki, T.M. Cotton, J. Phys. Chem. B 104 (2000) 2759.

[12] Z.Q. Feng, S. Imabayashi, T. Kakiuchi, K. Niki, J. Electroanal. Chem. 394 (1995) 149.

[13] R.A. Clark, E.F. Bowden, Langmuir 13 (1997) 559.

[14] M.C. Leopold, E.F. Bowden, Langmuir 18 (2002) 2239.

[15] A.E. Kasmi, J.M. Wallace, E.F. Bowden, S.M. Binet, R.J. Linderman, J. Am. Chem. Soc. 120 (1998) 225.

[16] A.E. Kasmi, J.M. Wallace, E.F. Bowden, S.M. Binet, R.J. Linderman,. J. Am. Chem. Soc. 120 (1998) 225.

[17] D. Hobara, S. Imabayashi, T. Kakiuchi, Nano Letters 2 (2002) 1021.

[18] S. Arnold, Z.Q. Feng, T. Kakiuchi, W. Knoll, K. Niki, J. Electroanal. Chem. 438 (1997) 91.

[19] M. Collinson, E. F. Bowden, M. J. Tarlov, Langmuir, 8 (1992) 1247.

[20] M. J. Tarlov, E. F. Bowden, J. Am. Chem. Soc. 113 (1991) 1847.

[21] T.M. Willey, A.L. Vance, C. Bostedt, T. van Buuren, R.W. Meulenberg, L.J. Terminello, C.S. Fadley, Langmuir, 20 (2004) 4939.

[22] M. Dijksma, B.A. Boukamp, B. Kamp, W.P. van Bennekom, Langmuir 18 (2002) 3105.

[23] M. Dijksma, B. Kamp, J.C. Hoogvliet, W.P. van Bennekom, Langmuir 16 (2000) 3852.

[24] G.E. Poirier, Chem. Rev. 97 (1997) 1117.

[25] K. Hu, A.J. Bard, Langmuir 14 (1998) 4790.

[26] K. A. Peterlinz, R. Georgiadis, Langmuir 12 (1996) 4731.

[27] Y.T. Kim, R.L. McCarley, A.J. Bard, Langmuir 9 (1993) 1941.

[28] Q. Cheng, A. Brajter-Toth, Anal. Chem. 67 (1995) 2767.

[29] E. Jeoung, T. H. Galow, J. Schotter, M. Bal, A. Ursache, M. T. Tuominen, C. M. Stafford, T. P. Russell and V. M. Rotello, Langmuir, 17 (2001) 6396.

[30] F.M. Hawkridge, T. Kuwana, Anal. Chem. 45 (1973) 1021.

[31] J. L. Willit, E. F. Bowden, J. Phys. Chem. 94 (1990) 8241.

[32] J. Vanderkooi, M. Brecinska, Arch. Biochem. Biophys. 162 (1974) 385.

[33] P. L. Dutton, D. F. Wilson, C. P. Lee, Biochemistry 9 (1970) 5077.

[34] J. Vanderkooi, M. Erecinska, B. Chance, Arch. Biochem. Biophys. 157 (1973) 531.

[35] M. T. Carter, M. Rodriguez, A. J. Bard, J. Am. Chem. Soc. 111 (1989) 8901.

[36] D. W. Pang, H. D. Abruña, Anal. Chem. 70 (1998) 3162.

[37] T. Pascher, J.P. Chesick, J.R. Winkler, H.B. Gray, Science 271 (1996) 1558.

[38] A. E. Kasmi, J. M. Wallace, E. F. Bowden, S.M. Binet, R. J. Linderman, J. Am. Chem. Soc. 120 (1998) 225.

[39] A.J. Bard, L.R. Faulkner, Electrochemical Methods: Fundamentals and Applications (Second 
Edition), John Wiley \& Sons, Inc., New York, 2001, p591.

[40] E. Laviron, J. Electroanal. Chem. 101 (1979) 19.

[41] B. Jin, S. Ding, K. Kametani, T. Nakamura, Chem. Lett. 34 (2005) 302.

[42] D. Hobara, M. Ota, S. Imabayashi, K. Niki, T. Kakiuchi, J.Electroanal. Chem. 444 (1998) 113.

[43] D. Hobara, K. Ueda, S. Imabayashi, M. Yamamoto, T. Kakiuchi, Electrochemistry 67 (1999) 1218.

[44] D. Hobara, T. Kakiuchi, Electrochem. Commun. 3 (2001) 154.

[45] C.D. Bain, G.M. Whitesides, J. Am. Chem. Soc. 111 (1989) 7164.

[46] J.P. Folkers, P.E. Laibinis, G.M. Whitesides, J. Phys. Chem. 98 (1994) 563.

[47] Y. Ooi, D. Hobara, M. Yamamoto, T. Kakiuchi, Langmuir 21 (2005) 11185.

[48] T. Kakiuchi, M. Iida, N. Gon, D. Hobara, S. Imabayashi, K. Niki, Langmuir 17 (2001) 1599.

[49] G.H. Barlow, E. Margoliash, J. Biol. Chem. 241 (1966) 1473.

[50] E. Shechter, P. Saludjian, Biopolymers 5 (1967) 788.

[51] P.D. Barker, A.G. Mauk, J. Am. Chem. Soc. 114 (1992) 3619.

\section{Figure legends:}

Fig. 1. Cyclic voltammograms of bare Au electrode (solid line) and the electrodes modified in $0.1 \mathrm{M} \mathrm{KCl}$ solution containing $1 \mathrm{mM}\left[\mathrm{Fe}(\mathrm{CN})_{6}\right]^{3-} /\left[\mathrm{Fe}(\mathrm{CN})_{6}\right]^{4-}$. The ratios of T-COOH to T-NH${ }_{2}$ are 5:0 (dotted line), 4:1 (short dotted line) and 3:2 (dashed line) in adsorption. Scan rate: $20 \mathrm{mV} \mathrm{s}^{-1}$.

Fig. 2. Percentage change in double layer capacitance of electrode modified with different ratios of $\mathrm{T}-\mathrm{COOH}$ to $\mathrm{T}-\mathrm{NH}_{2}$ relative to the bare electrode.

Fig. 3. Cyclic voltammograms of T-COOH$+\mathrm{T}-\mathrm{NH}_{2} \mid \mathrm{Au}$ electrode (T-COOH:T-NH $\mathrm{N}_{2}=3: 2$ in adsorption 
solution) in $4 \mathrm{mM} \mathrm{PBS} \mathrm{(pH} \mathrm{7.0)} \mathrm{containing} 0.05 \mathrm{mg} \mathrm{mL}^{-1}$ cyt c during the first 20 cycles. Scan rate: 20 $\mathrm{mV} \mathrm{s}^{-1}$.

Fig. 4. Cyclic voltammograms of T-COOH+T-NH$H_{2} \mid \mathrm{Au}$ electrode (T-COOH:T-NH$=3: 2$ in adsorption solution) in various concentrations of cyt c in 4 mM PBS ( $\mathrm{pH}$ 7.0) after scanning 20 cycles. (a) 0.00 , (b) 0.05 , (c) 0.10 , (d) 0.50 , and (e) $1.00 \mathrm{mg} \mathrm{mL}^{-1}$ cyt c. Scan rate: $20 \mathrm{mV} \mathrm{s}^{-1}$.

Fig. 5. Cyclic voltammograms of cyt c/T-COOH+T-NH$H_{2} \mid A u$ electrode (T-COOH:T-NH ${ }_{2}=3: 2$ in adsorption solution) in $10 \mathrm{mM}$ PBS (pH 7.0, cyt c free) after adsorption from the solutions of (a) 0.00, (b) 0.05, (c) 0.10 , (d) 0.50 , and (e) $1.00 \mathrm{mg} \mathrm{mL}^{-1}$ cyt c. Scan rate: $40 \mathrm{mV} \mathrm{s}^{-1}$.

Fig. 6. Relationship between reduction peak currents and potential scan rate using cyt c/T-COOH $+\mathrm{T}-\mathrm{NH}_{2} \mid \mathrm{Au}$ electrode (T-COOH:T- $\mathrm{NH}_{2}=3: 2$, [cyt c] $=0.05 \mathrm{mg} \mathrm{mL}^{-1}$ in adsorption solution) in $10 \mathrm{mM}$ PBS (pH 7.0, cyt c free).

Fig. 7. Effect of $\mathrm{pH}$ on the potential of cyt $\mathrm{c} / \mathrm{T}-\mathrm{COOH}+\mathrm{T}-\mathrm{NH}_{2} \mid \mathrm{Au}$ electrode (T-COOH:T-NH $\mathrm{N}_{2}=3: 2$ in adsorption solution) in $10 \mathrm{mM}$ PBS (pH 7.0) at a scan rate of $200 \mathrm{mV} \mathrm{s}^{-1}$.

Scheme 1. Schematic diagram for immobilizing cyt $\mathrm{c}$ on the mixed SAMs of T-COOH and T-NH 2 .

\section{Table}

Table 1

Electrochemical parameters for the modified gold electrode prepared with various ratios of T-COOH to

$\mathrm{T}-\mathrm{NH}_{2}$

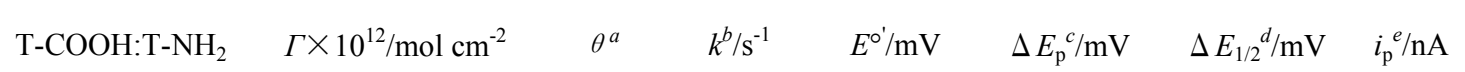




\begin{tabular}{llllllll}
\hline $5: 0$ & 5.0 & 0.35 & $9.5 \pm 0.7$ & -32 & 36 & 107 & 12 \\
$4: 1$ & 7.8 & 0.55 & $9.2 \pm 0.6$ & -23 & 28 & 105 & 24 \\
$3: 2$ & 9.2 & 0.64 & $15.8 \pm 0.6$ & -32 & 10 & 91 & 26 \\
$1: 1$ & 7.4 & 0.52 & $15.2 \pm 0.6$ & -33 & 20 & 98 & 19 \\
$2: 3$ & 6.1 & 0.43 & $14.5 \pm 0.4$ & -23 & 19 & 103 & 18 \\
$1: 4$ & 3.1 & 0.22 & $13.7 \pm 0.6$ & -29 & 24 & 105 & 9 \\
$0: 5$ & 2.6 & 0.18 & $14.0 \pm 0.8$ & -23 & 22 & 105 & 8 \\
\hline
\end{tabular}

${ }^{a} \theta$ is the fraction of monolayer coverage by cyt $\mathrm{c}$ based on an electrode geometric area of $0.314 \mathrm{~cm}^{2}$ and the theoretical monolayer concentration of $14.3 \times 10^{-12} \mathrm{~mol} \mathrm{~cm}^{-2}$.

${ }^{b}$ Aveage of measurements with different scan rate $\pm s$.

${ }^{c}$ Scan rate: $40 \mathrm{mV} \mathrm{s}^{-1}$.

${ }^{d}$ Scan rate: $100 \mathrm{mV} \mathrm{s}^{-1} ; \Delta E_{1 / 2}$ is the total width at half-height of the wave.

${ }^{e}$ Scan rate: $100 \mathrm{mV} \mathrm{s}^{-1}$.

\section{Figures}




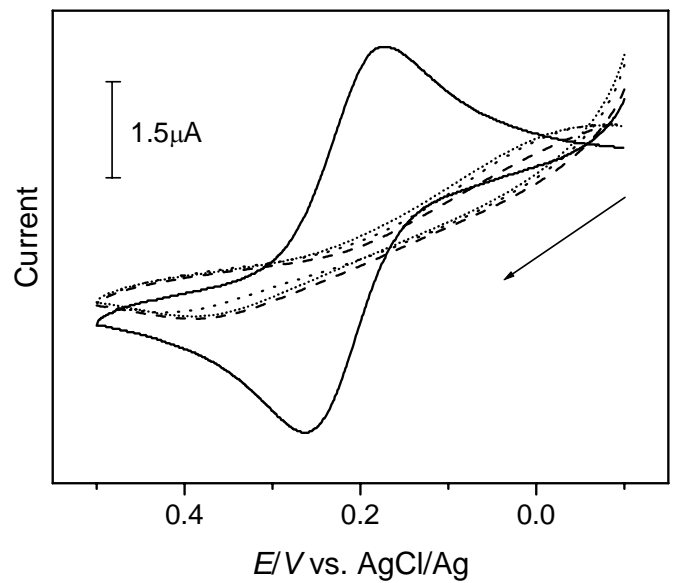

Fig. 1

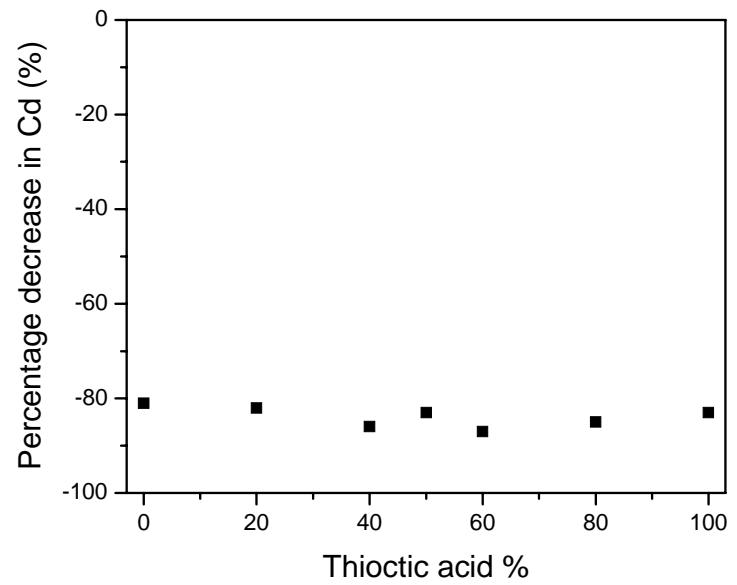

Fig. 2

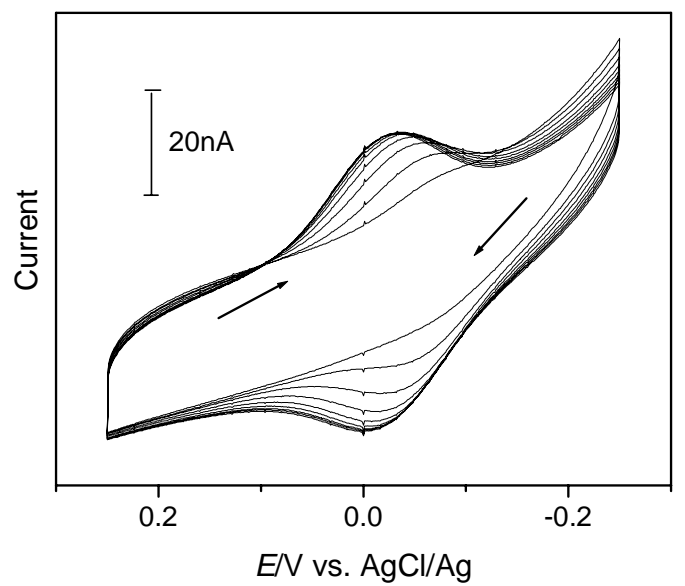

Fig. 3 


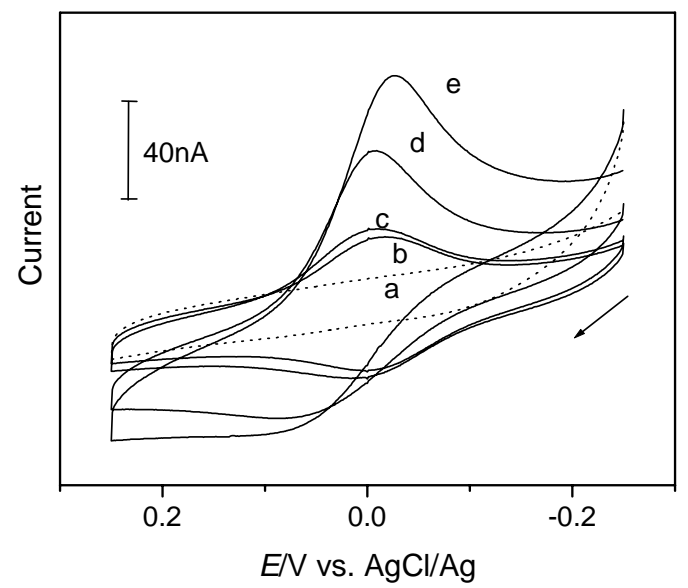

Fig. 4

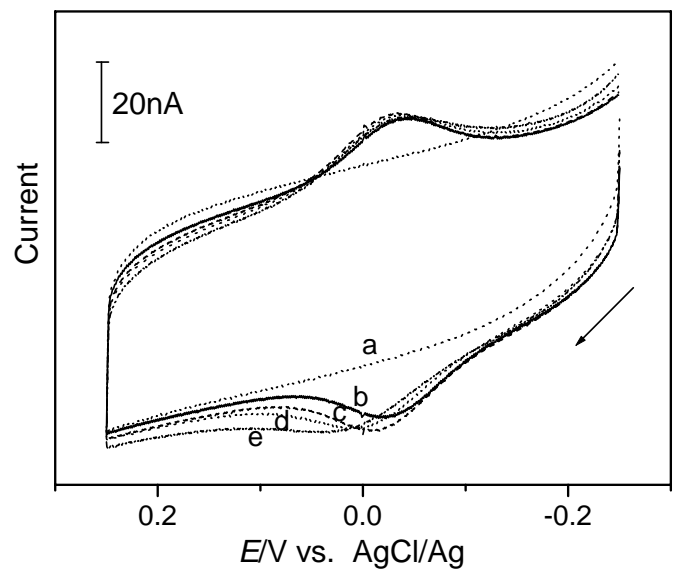

Fig. 5

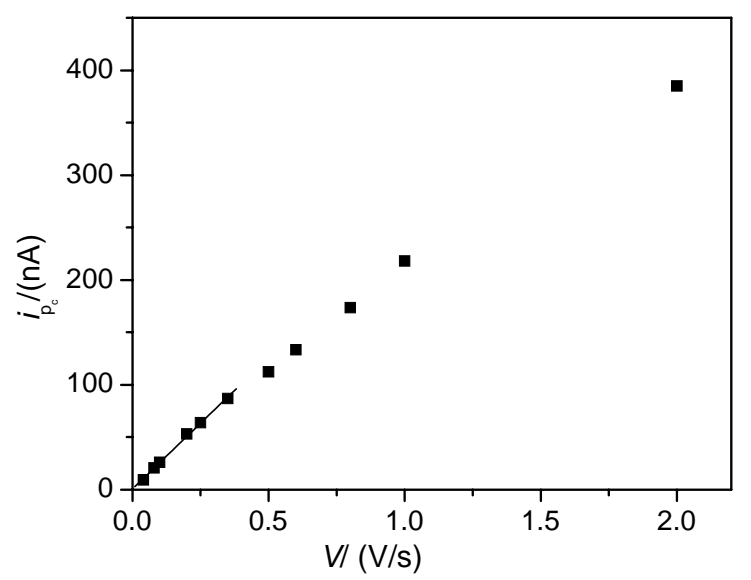

Fig. 6 


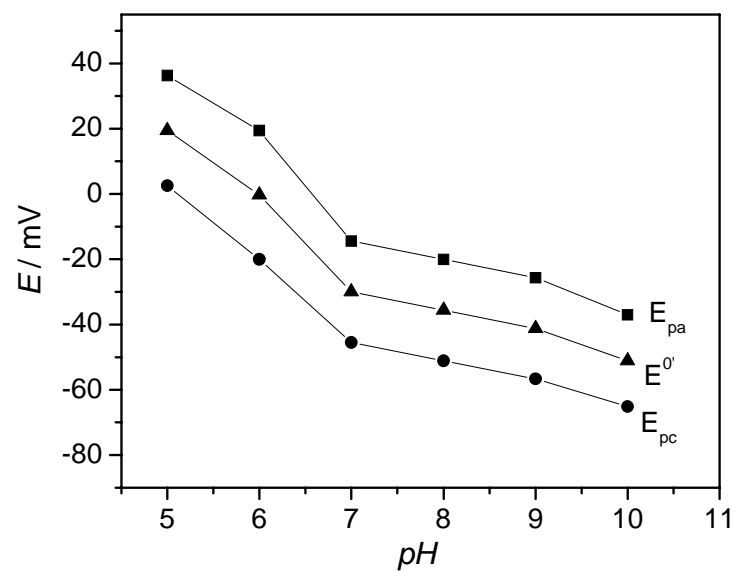

Fig. 7

\section{Scheme}

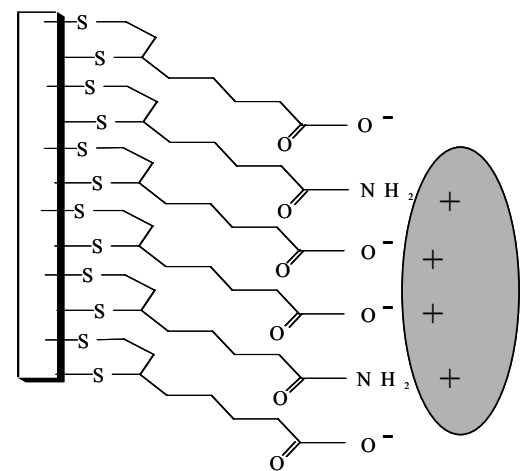

$\begin{array}{lll}\mathrm{Au} & \text { SAMs } & \text { cyt c }\end{array}$

Scheme 1. 